\title{
Genetic variations of the porcine PRKAG3 gene in Chinese indigenous pig breeds
}

\author{
Lu-Sheng Huang*, Jun-Wu Ma, Jun Ren, Neng-Shui Ding, \\ Yuan-Mei Guo, Hua-Shui Ai, Lin Li, Li-Hua Zhou, \\ Cong-Ying CHEN
}

Key Laboratory for Animal Biotechnology of Jiangxi Province and the Ministry of Agriculture of China, Jiangxi Agricultural University, Nanchang, 330045, P.R. China

(Received 31 October 2003; accepted 25 March 2004)

\begin{abstract}
Four missense substitutions (T30N, G52S, V199I and R200Q) in the porcine $P R K A G 3$ gene were considered as the likely candidate loci affecting meat quality. In this study, the $R 200 Q$ substitution was investigated in a sample of 62 individuals from Hampshire, Chinese Min and Erhualian pigs, and the genetic variations of T30N, G52S and V199I substitutions were detected in 1505 individuals from 21 Chinese indigenous breeds, 5 Western commercial pig breeds, and the wild pig. Allele 200R was fixed in Chinese Min and Erhualian pigs. Haplotypes $I I-Q Q$ and $I V-Q Q$ were not observed in the Hampshire population, supporting the hypothesis that allele $200 Q$ is tightly linked with allele $199 \mathrm{~V}$. Significant differences in allele frequencies of the three substitutions (T30N, G52S and V199I) between Chinese indigenous pigs and Western commercial pigs were observed. Obvious high frequencies of the "favorable" alleles $30 T$ and $52 G$ in terms of meat quality were detected in Chinese indigenous pigs, which are well known for high meat quality. However, the frequency of the "favorable" allele 199I, which was reported to have a greater effect on meat quality in comparison with $30 T$ and $52 G$, was very low in all of the Chinese indigenous pigs except for the Min pig. The reasons accounting for this discrepancy remain to be addressed. The presence of the three substitutions in purebred Chinese Tibetan pigs indicates that the three substitutions were ancestral mutations. A novel A/G substitution at position 51 in exon 1 was identified. The results suggest that further studies are required to investigate the associations of these substitutions in the PRKAG3 gene with meat quality of Chinese indigenous pigs, and to uncover other polymorphisms in the PRKAG3 gene with potential effects on meat quality in Chinese indigenous pigs.
\end{abstract}

pig / PRKAG3 gene / meat quality

\section{INTRODUCTION}

The protein kinase adenosine monophosphate-activated $\gamma 3$-subunit (PRKAG3) gene encodes the muscle specific isoform of the regulatory $\gamma 3$

*Corresponding author: Lushenghuang@hotmail.com 
subunit of adenosine monophosphate activated protein kinase (AMPK), which plays a key role in regulating energy homeostasis in eukaryotes. A nonconserved substitution $(R 200 Q)$ in the PRKAG3 gene was initially characterized in Hampshire pigs [6], resulting in an approximate 70\% increase in muscle glycogen content with large effects on meat quality and processing yields $[2,3]$. Three additional economically important missense substitutions (T30N, G52S and V199I) in the porcine PRKAG3 gene were recently identified with additive effects on the glycogen content in muscle and meat quality traits [1]. The PRKAG3 gene was therefore supposed to be a functional gene significantly affecting meat quality traits in pigs. China has abundant indigenous pig breeds that are well known for high meat quality. Here we report on the genetic variations of four missense substitutions (T30N, G52S, $V 199 I$ and $R 200 Q$ ) in the PRKAG3 gene in Chinese indigenous pigs in order to provide new evidence of the effects of the PRKAG3 gene on meat quality.

\section{MATERIALS AND METHODS}

\subsection{Animals}

Three single nucleotide polymorphisms (SNP) of the porcine PRKAG3 gene (T30N, G52S and V199I) were genotyped using 1505 individuals from 21 Chinese indigenous pig breeds, 5 Western commercial pig breeds and wild pigs (Tab. I). Samples were chosen avoiding full sib animals. Allele frequencies at the $R 200 Q$ mutation site were estimated in 37 purebred unrelated Hampshire individuals, 13 unrelated Min pigs and 12 unrelated Erhualian pigs. SNP screening was performed using 18 founder animals (2 White Duroc and 16 Chinese Erhualian) of a three-generation intercross between White Duroc $\times$ Chinese Erhualian. Genomic DNA were isolated from ear tissues by phenol/chloroform extraction [4].

\subsection{SNP genotyping}

PCR-HphI (forward: 5'-ATG AGC TTC CTA GAG CAA GGA G-3'; reverse: 5'-GGC TGC ATG ATG TTA TGT GCC T-3') and PCR-BsaHI/BsrBI (forward: 5'-GGA GCA AAT GTG CAG ACA AG-3'; reverse: 5'- CCC ACG AAG CTC TGC TTC TT-3') were adopted to detect G52S, V199I and R200Q substitutions, respectively [1]. PCR primers (forward: 5'-CAT CCC GAG CTG TAA CCA CC-3'; reverse: 5'- GCC TTG AAC TCA CCT TCC CT-3') were designed and a PCR-StyI approach was taken to detect T30N substitution. PCR reactions were performed in a PTC100 thermocycler (MJ Research, 
Waltham, USA) in a final volume of $15 \mu \mathrm{L}$ containing $50 \mathrm{ng}$ of porcine genomic DNA, $1.5 \mathrm{mM} \mathrm{MgCl}_{2}, 0.125 \mathrm{mM}$ of each dNTP, $0.3 \mu \mathrm{M}$ of each primer and $1 \mathrm{U}$ Taq DNA polymerase with $10 \times$ PCR buffer (MBI, Shanghai, China). PCR profiles were 35 cycles of $94{ }^{\circ} \mathrm{C}$ for $30 \mathrm{~s}, 56 \sim 59{ }^{\circ} \mathrm{C}$ for $40 \mathrm{~s}$ and $72{ }^{\circ} \mathrm{C}$ for $30 \mathrm{~s}$ with an initial denaturation at $94{ }^{\circ} \mathrm{C}$ for $6 \mathrm{~min}$ and a final extension at $72{ }^{\circ} \mathrm{C}$ for $5 \mathrm{~min}$. PCR products were digested with $2 \mathrm{U}$ restriction enzymes at $37^{\circ} \mathrm{C}$ for $12 \mathrm{~h}$, and the restriction fragments were separated on $4 \%$ agarose gels stained with ethidium bromide.

\subsection{DNA sequencing and SNP identification}

PCR products representing different genotypes at the four PRKAG3 SNP loci were purified using a QIAquick PCR Purification Kit (QIAGEN, Hilden, Germany), and were bi-directionally sequenced with the respective PCR primers using the ABI PRISM ${ }^{\circledR}$ BigDye $^{\mathrm{TM}}$ Terminator Cycle Sequencing Kit (v3.0) and an ABI PRISM ${ }^{\circledR} 3100$ Genetic Analyzer (Applied Biosystems, Foster City, USA). The sequence identity was compared by the Gapped BLAST program (http://www.ncbi.nih.gov), and the sequences of 18 founder animals were aligned by the application of the program SeqMan (DNAStar software package, http://www.lynnon.com) to identify the putative SNP.

\section{RESULTS AND DISCUSSIONS}

\subsection{T30N, G52S and V199I substitutions}

Allele frequencies at the T30N, G52S and V199I polymorphic loci in 21 Chinese indigenous pigs, 5 Western commercial pigs and the wild pig are summarized in Table I. Chinese indigenous pig breeds belonging to the same ecotype had more similar allele frequency distribution. Western commercial pigs had higher polymorphism information content (PIC) at the three SNP loci compared with most of the Chinese indigenous pigs. The differences of allele frequencies between most of the Chinese indigenous pigs and Western commercial pigs were significant $(P<0.05$, data not shown). The genetic variations at the three SNP loci in Landrace, Large White and Duroc studied here were similar to those reported previously [1], although some tiny deviations were observed, presumably due to the smaller sample size in this study.

The $30 T$ and $52 G$ alleles were reported to be favorable in terms of meat quality [1]. As expected, the $30 T$ and $52 G$ alleles were the predominant alleles 
Table I. Allele frequencies of the T30N, G52S and V199I substitutions in the PRKAG3 gene in 27 pig breeds.

\begin{tabular}{|c|c|c|c|c|c|c|c|c|c|}
\hline \multirow{3}{*}{ Type } & \multirow{3}{*}{ Breed } & \multicolumn{8}{|c|}{ Locus } \\
\hline & & \multirow{2}{*}{ No. } & T30N & \multirow{2}{*}{ No. } & G52S & \multirow{2}{*}{ No. } & \multirow{2}{*}{$\begin{array}{l}\text { V199I } \\
\mathrm{I}\end{array}$} & \multirow{2}{*}{ No. } & \multirow{2}{*}{$\begin{array}{l}R 200 Q \\
R\end{array}$} \\
\hline & & & $\mathrm{T}$ & & $\mathrm{G}$ & & & & \\
\hline \multirow[t]{5}{*}{1} & Landrace & 50 & 0.65 & 61 & 0.73 & 61 & 0.09 & -- & -- \\
\hline & Large White & 61 & 0.85 & 65 & 0.52 & 64 & 0.21 & -- & -- \\
\hline & Duroc & 46 & 0.35 & 66 & 0.89 & 64 & 0.24 & -- & -- \\
\hline & Hampshire & 38 & 0.89 & 60 & 0.79 & 60 & 0.30 & 37 & 0.65 \\
\hline & Pietrain & 11 & 0.95 & 11 & 0.73 & 11 & 0.68 & -- & -- \\
\hline \multirow[t]{2}{*}{2} & Min & 42 & 1 & 42 & 1 & 42 & 0.38 & 13 & 1 \\
\hline & Bamei & 60 & 1 & 60 & 1 & 60 & 0.10 & -- & -- \\
\hline \multirow[t]{4}{*}{3} & Bama Xiang & 12 & 0.96 & 61 & 1 & 61 & 0 & -- & -- \\
\hline & Luchuan & 62 & 0.94 & 62 & 1 & 62 & 0.01 & -- & -- \\
\hline & Huai & 60 & 1 & 60 & 0.99 & 60 & 0.03 & -- & -- \\
\hline & Lin'gao & 72 & 0.83 & 72 & 0.99 & 72 & 0.07 & -- & -- \\
\hline \multirow[t]{2}{*}{4} & Erhualian & 76 & 0.99 & 76 & 1 & 76 & 0.01 & 12 & 1 \\
\hline & Jiangquhai & 47 & 1 & 47 & 1 & 47 & 0.01 & -- & -- \\
\hline \multirow[t]{8}{*}{5} & Guangdong spotted & 57 & 0.67 & 57 & 0.85 & 57 & 0 & -- & -- \\
\hline & $\begin{array}{l}\text { Jinhua black } \\
\text { head-hind }\end{array}$ & 59 & 1 & 59 & 1 & 59 & 0 & -- & -- \\
\hline & Leping spotted & 48 & 1 & 48 & 0.93 & 48 & 0 & -- & -- \\
\hline & Wanan spotted & 61 & 1 & 61 & 1 & 61 & 0.13 & -- & -- \\
\hline & Yushan black & 60 & 1 & 60 & 1 & 60 & 0.14 & -- & -- \\
\hline & $\begin{array}{l}\text { Shanggao black } \\
\text { head-hind }\end{array}$ & 60 & 1 & 60 & 1 & 60 & 0 & -- & -- \\
\hline & Doxiang spotted & 55 & 1 & 55 & 0.87 & 55 & 0 & -- & -- \\
\hline & Xiushui Hang & 61 & 1 & 61 & 0.98 & 61 & 0 & -- & -- \\
\hline 6 & Wujing & 63 & 0.93 & 63 & 0.96 & 63 & 0 & -- & -- \\
\hline \multirow[t]{4}{*}{7} & Diqing Tibetan pig & 32 & 1 & 65 & 0.95 & 61 & 0.07 & -- & -- \\
\hline & Litang Tibetan pig & 46 & 1 & 46 & 1 & 46 & 0 & -- & -- \\
\hline & Hezuo Tibetan pig & 21 & 0.98 & 61 & 1 & 61 & 0.01 & -- & -- \\
\hline & Milin Tibetan pig & 24 & 1 & 60 & 0.81 & 60 & 0.02 & -- & -- \\
\hline 8 & Wild pig & 6 & 1 & 6 & 1 & 6 & 0 & -- & -- \\
\hline
\end{tabular}

Group 1 refers to western commercial pig breeds and Group 8 refers to the Chinese wild pig. Group 2, 3, 4, 5, 6 and 7 are Chinese indigenous pig breeds which were classified into six ecotypes including the Northern China type, the Southern China type, the Low Yangtze River Basin Type, the Central China type, the Southeastern China type and the High Plateau type according to their appearance, origin, productive characteristics and geographical distribution. 
in all Chinese indigenous pigs, which was consistent with the fact that Chinese indigenous pigs generally have flavorful meat quality [5].

Amongst the T30N, G52S and V199I substitutions, the largest effects on meat quality were obtained with the V199I substitution with the $199 I$ allele being the favorable allele for high meat quality in the association study [1]. A high frequency of the 199 I allele was observed in Berkshire pigs which are known for good meat quality in Western commercial pigs [1]. Surprisingly, the frequencies of the favorable allele 199I were very low in all of the Chinese indigenous pigs except for Min pigs. The explanations for the discrepancy might be the following: (1) the effects of V199I substitution on the meat quality of Chinese indigenous pigs are different from those of Western commercial pigs; (2) other unrevealed substitutions in the PRKAG3 gene or other functional genes with significant favorable effects in meat quality exist in Chinese indigenous pigs, which ameliorate the negative effects of the $199 \mathrm{~V}$ allele in terms of meat quality in Chinese indigenous pigs. Further SNP screening and identification of the porcine PRKAG3 gene are worthwhile.

All three substitutions were observed in Chinese Tibetan pigs. Few exotic pig breeds have been introduced into the Qinghai-Tibet plateau, the habitat of Chinese Tibetan pigs, because of geographical isolation. The existence of T30N, G52S and V199I substitutions in purebred Chinese Tibetan pigs indicates that the three substitutions were ancestral mutations.

Berkshire pigs were initially developed in Britain in the middle of the nineteenth century by crossing local pigs in England (the basic Berkshire stock) with Siamese and Chinese Guangdong spotted pigs, which were introduced into Britain in the 1770s [5]. The 199I allele was not found in the 57 Guangdong spotted pigs, indicating that tracing the high frequency of the $199 \mathrm{I}$ allele in Berkshire pigs probably originated from local pigs in England or Siamese pigs.

\section{2. $R 200 Q$ substitution}

The $R 200 Q$ substitution in the PRKAG3 gene was shown to be a causative mutation underlying the large differences in meat quality and processing yield in Hampshire pigs [6]. The allele frequencies of $200 R$ and $200 Q$ in the Hampshire population in this study were $65 \%$ and $35 \%$, respectively (Tab. I). The ratio of $R N^{-}$carriers ( $R Q$ and $Q Q$ individuals) was $57 \%$, which was less than that of $86 \%$ evaluated by a glycolytic potential in American Hampshire populations [7]. The II- $Q Q$ and $I V-Q Q$ haplotypes were not found in the Hampshire population in this study (data not shown), supporting the hypothesis that $200 Q$ 
is tightly linked with $199 \mathrm{~V}$ [1]. No $200 \mathrm{Q}$ allele was present in the Chinese Min and Erhualian pigs, consistent with the fact that the $200 Q$ allele is observed mainly in Hampshire pigs $[1,6]$.

\subsection{SNP identification}

A novel SNP, $A / G$ transversion at position 51 in exon 1, was identified in the PCR1 amplicon; the synonymous mutation does not alter the encoding amino acid. The $A / G$ substitution was verified by the alignment of two porcine PRKAG3 gene sequences deposited in the database (Genbank accession no. AF214521 and AX398341.1, data not shown).

\section{ACKNOWLEDGEMENTS}

This study was financially supported by the National Natural Science Foundation of China (30060058) and the National 973 project 2003CCA00600.

\section{REFERENCES}

[1] Ciobanu D., Bastiaansen J., Malek M., Helm J., Woollard J., Plastow G., Rothschild M., Evidence for new alleles in the protein kinase adenosine monophosphate-activated $\gamma 3$-subunit gene associated with low glycogen content in pig skeletal muscle and improved meat quality, Genetics 159 (2001) $1151-1162$.

[2] Gariépy C., Godbout D., Fernandez X., Talmant A., Houde A., The effect of $R N$ gene on yields and quality of extended cooked cured hams, Meat Science 52 (1999) 57-64.

[3] Le Roy P., Elsen J.M., Caritez J.C., Talmant A., Juin H., Sellier P., Monin G., Comparison between the three porcine $\mathrm{RN}$ genotypes for growth, carcass composition and meat quality traits, Genet. Sel. Evol. 32 (2000) 165-186.

[4] Lu S.D., Current protocols for molecular biology, 2nd edn, Higher Education Press, China, 1999.

[5] Lu Z.X., Guo C.J., The theory and practice of current pork production, Chinese Agricultural Science Press, China, 1995.

[6] Milan D., Jeon J.T., Looft C., Amarger V., Robic A., Thelander M., RogelGaillard C., Paul S., Iannuccelli N., Rask L., Ronne H., Lundstrom K., Reinsch N., Gellin J., Kalm E., Roy P.L., Chardon P., Andersson L., A mutation in PRKAG3 associated with excess glycogen content in pig skeletal muscle, Science 288 (2000) 1248-1251.

[7] Miller K.D., Ellis M., Mckeith F.K., Bidner B.S., Meisinger D.J., Frequency of the Redement Napole $R N^{-}$allele in a population of American Hampshire pigs, J. Anim. Sci. 78 (2000) 1811-1815. 